\title{
Belphégor
}

Littérature populaire et culture médiatique

$17 \mid 2019$

Mutations des légitimités dans les productions

culturelles contemporaines

\section{Coudray, Jean-Luc, Émile Salgari. Les vantards de la mer}

\section{Vittorio Frigerio}

\section{(2) OpenEdition \\ Journals}

Electronic version

URL: https://journals.openedition.org/belphegor/1533

DOI: $10.4000 /$ belphegor.1533

ISSN: 1499-7185

Publisher

LPCM

Electronic reference

Vittorio Frigerio, "Coudray, Jean-Luc, Émile Salgari. Les vantards de la mer", Belphégor [Online], 17 | 2019,

Online since 16 April 2019, connection on 25 August 2021. URL: http://journals.openedition.org/

belphegor/1533 ; DOI: https://doi.org/10.4000/belphegor.1533

This text was automatically generated on 25 August 2021.

\section{(c)}

Belphégor est mis à disposition selon les termes de la Licence Creative Commons Attribution - Pas d'Utilisation Commerciale - Pas de Modification 4.0 International. 


\title{
Coudray, Jean-Luc, Émile Salgari. Les vantards de la mer
}

\author{
Vittorio Frigerio
}

\section{REFERENCES}

Coudray, Jean-Luc, Émile Salgari. Les vantards de la mer. Bordeaux : Éditions Zeraq, 2018. 96 p. ISBN : 9791093860282.

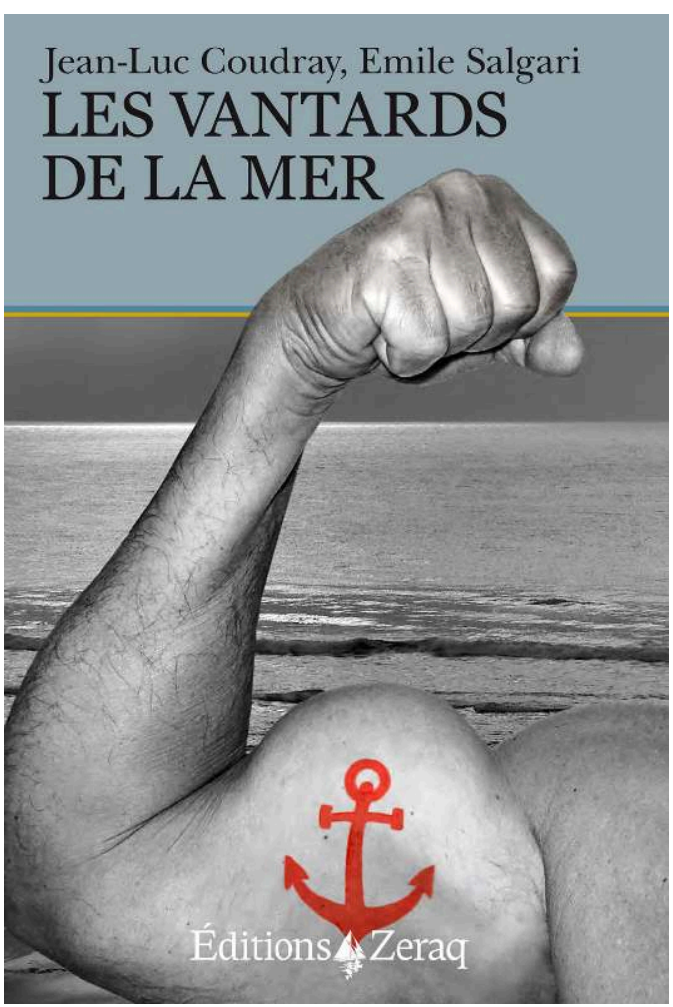


1 C'est toujours une bonne nouvelle de voir reproposer des textes de Salgari en traduction française. Les éditions Zeraq, qui se font une spécialité des thèmes reliés à la mer et à la navigation, ont décidé de combiner en un seul mince volume certaines histoires tirées des Novelle marinaresche di Mastro Catrame et une nouvelle d'un auteur contemporain, Jean-Luc Coudray, surtout connu comme scénariste et auteur de bandes dessinées, défini en quatrième de couverture «explorateur ironique du malaise contemporain ». Il est vrai que la nouvelle de Coudray, qui donne le titre au volume - et qui se compose en fait de deux histoires indépendantes dont le parcours va s'unir à la fin - suscite facilement le sourire et se lit avec plaisir.

2 De Salgari, on a droit à trois textes de longueur variable. Le premier - « Un loup de mer » - étant la nouvelle introductive du recueil original, présentant le personnage du narrateur, et le troisième - «L'apparition du naufragé » - la dernière nouvelle du livre. On retrouve également « Le sceau de Salomon », la cinquième nouvelle du recueil.

Les inconditionnels du romancier de Vérone seront excusés de regretter de ne pas avoir eu plutôt une traduction du livre complet. Cela d'autant plus que la traductrice, Delphine Gachet, a fait un travail louable et a rendu le style salgarien avec aisance dans un français que les lecteurs d'aujourd'hui apprécieront. Quelques vétilles demeurent. Une « eau bénie » qui devrait être « bénite », un « Messer Belzebuth » qui aurait dû être "messire», d'autres menus détails si on veut être pénible (quand Salgari déforme l'anglais, parlant de "bosman », une note explicative pourrait s'avérer utile). Mais ce ne sont effectivement que des vétilles. On se demande en revanche si les nouvelles choisies, au ton plutôt horrifique, cadrent véritablement avec le projet du livre, présenté dans la charmante introduction de Dario Pontuale ( Sous le masque du visage ») comme étant de se situer dans la lignée de Plaute et de Goldoni, revisitant la figure du miles gloriosus transposée sur les flots de l'océan. Si « Mastro Catrame » est un affabulateur - fort réticent par ailleurs - il cadre peu à notre avis avec la catégorie des "vantards", dont la nouvelle de Coudray donne en revanche un portrait tout à fait drôle quoique fortement typé.

Cela dit, on lira avec agrément ce petit volume, tout en espérant que cette initiative pourra susciter d'autres nouvelles traductions des œuvres d'Emilio Salgari (francisé ici en «Émile » «selon l'ancienne écriture traditionnelle en France », ce qui peut paraître un choix quelque peu étrange alors que bien d'autres traductions actuellement disponibles gardent le nom original).

\section{AUTHOR \\ VITTORIO FRIGERIO}

Dalhousie University 